\title{
Reinstatement of Morphine-Induced Conditioned Place Preference in Mice by Priming Injections
}

\author{
B. Ribeiro Do Couto, M.A. Aguilar, C. Manzanedo, M. Rodríguez-Arias and J. Miñarro \\ Departamento de Psicobiología, Facultad de Psicología, Universitat de Valencia, \\ Avda. Blasco Ibáñez, 21. 46010 Valencia, Spain.
}

\begin{abstract}
To construct a model of relapse of drug abuse in mice, the induction, we evaluated the extinction and reinstatement of morphineinduced place preference. In Experiment 1, we examined the effects of morphine $(0,2,3,5,10$, 20 and $40 \mathrm{mg} / \mathrm{kg}$ ) in the conditioned place preference (CPP) paradigm. Mice showed CPP with 5, 10, 20 and $40 \mathrm{mg} / \mathrm{kg}$. In Experiment 2, we evaluated the effects of two different extinction procedures. After conditioning with 40 $\mathrm{mg} / \mathrm{kg}$ of morphine, the mice underwent daily extinction sessions of 60 or $15 \mathrm{~min}$ of duration. CPP was extinguished after seven and nine sessions, respectively. In Experiment 3, we tested the reinstating effects of several priming doses of morphine. Mice were conditioned with $40 \mathrm{mg} / \mathrm{kg}$ of morphine and underwent the daily 15 min extinction sessions until CPP was no longer evident. Then, the effects of morphine $(0$, $2,3,5,10,20,40 \mathrm{mg} / \mathrm{kg}$, i.p.) were evaluated. CPP was reinstated by doses from $5 \mathrm{mg} / \mathrm{kg}$ upward. The results show that morphine priming injections are effective in reactivating opiateseeking behavior in mice, and thus, the CPP paradigm might be useful to investigate the mechanisms underlying relapse of drug abuse.
\end{abstract}

Reprint requests to: Jose Miñarro, Departamento de Psicobiología, Facultad de Psicología, Universitat de Valencia, Avda. Blasco Ibáñez, 21, 46010 Valencia, Spain.; email: jose.minarro@uv.es

\section{KEYWORDS}

morphine, conditioned place preference, extinction, reinstatement, relapse, mice

\section{INTRODUCTION}

Relapse to drug use after prolonged periods of abstinence is a common feature of drug addiction and remains the primary problem in treating drug abuse. Drug craving and relapse to drug-using behavior are seen after many years of withdrawal in individuals who have been addicted to heroin and cocaine (Mendelson \& Mello, 1996; O'Brien, 1997) when confronted with the self-administered drug (de Wit, 1996), with stimuli previously associated with drug taking (Carter \& Tiffany, 1999), or with stress (Sinha et al., 1999).

Traditionally, the animal model used to study relapse to drug seeking has been the extinctionreinstatement of i.v. self-administration. In this model, laboratory animals are trained to make a response, such as pressing a lever, to selfadminister a drug and after the extinction of that behavior, the ability of several stimuli to reinstate the response is determined (Carrol \& Comer, 1996). A priming injection of the previously selfadministered drug, the presentation of environmental cues associated with drug taking, and the exposure to stressors results in the reinstatement of responding (Shalev et al., 2002). 
Recently, several laboratories have commenced the use of the place conditioning procedure to study the relapse phenomenon to cocaine and opiates and confirmed the idea that exposure to the drug (Mueller \& Stewart, 2000; Wang et al., 2000; Parker \& McDonald, 2000; Manzanedo et al., 2001a; Itzhak \& Martin, 2002; Li et al., 2002; Lu et al., 2002; Mueller et al., 2002; Szumlinski et al., 2002), to environmental cues associated with the drug (Lu et al., 2002) and to stress (Wang et al., 2000; Sanchez \& Sorg, 2001; Wang et al., 2001) are the main factors inducing relapse to drug seeking. Most studies, however, have been performed in rats, and the reinstatement effects of morphine on a previously extinguished morphine-induced CPP has not been evaluated in mice, with the exception of an initial study in our laboratory, where it was observed that a noncontingent injection of morphine was able to reinstate an extinguished CPP (Manzanedo et al., 2001a). Because of the widespread use of mice as experimental subjects in behavioral pharmacology and because the mouse is still the only species in which knockout techniques are well established, in the present work we attempt to develop a model to study drug-induced relapse to opiate addiction. With this purpose, we performed three experiments. First, the rewarding effect of different doses of morphine in CPP paradigm was investigated. Second, the duration of conditioning effects when mice under-went a natural extinction procedure was studied. Finally, the reinstating effect of different doses of morphine on the previously extinguished morphine-induced CPP was evaluated.

\section{EXPERIMENTAL}

\section{Subjects and apparatus}

A total of 198 male mice of the OF1 strain acquired commercially in Charles River (Barcelona, Spain) arrived at the laboratory at 42 days of age and were housed in groups of 5 in plastic cages (25 x $25 \mathrm{~cm}) 10$ days before experiments, under the following conditions: constant temperature $(21 \pm$ $2{ }^{\circ} \mathrm{C}$ ), reversed light schedule (white lights on: 19:30 to $07: 30 \mathrm{~h}$ ), with food and water available ad libitum, except during behavioral tests. The procedures involving the mice and their care were conducted in conformity with national, regional and local laws and regulations, in accordance with the European Communities Council Directives (86/609/EEC, 24 November 1986).

Four identical Plexiglas boxes with two equal size compartments $(30.7 \mathrm{~cm}$ long $\times 31.5 \mathrm{~cm}$ wide $\mathrm{x}$ $34.5 \mathrm{~cm}$ high), separated by a gray central area $(13.8 \mathrm{~cm}$ long $\times 31.5 \mathrm{~cm}$ wide $\times 34.5 \mathrm{~cm}$ high) were used. The compartments have different colored walls (black vs. white) and also distinct floor textures (fine grid in the black compartment and wide grid in the white one). Four infrared light beams in each compartment of the box and six in the central area allowed the recording of the position of the animal and its crossings from one compartment to the other. The equipment was controlled by an IBM PC using MONPRE $2 \mathrm{Z}$ software (CIBERTEC, SA, Spain).

\section{Treatment and procedure}

Animals were injected intraperitoneally (i.p.) with morphine (Laboratorios Alcaliber, Madrid, Spain), in a volume of $0.01 \mathrm{~mL} / \mathrm{g}$. Control groups were injected with physiological saline $(\mathrm{NaCl}$ $0.9 \%$ ), also used to dissolve the drugs. The experiment, consisting of three phases, was carried out during the dark cycle following a procedure unbiased in terms of initial spontaneous preference (for details see Manzanedo et al., 2001b). During the first phase or pre-conditioning (Pre-C), mice were given access to both compartments of the apparatus for $15 \mathrm{~min}(900 \mathrm{~s})$ each day for $3 \mathrm{~d}$. On day 3 , the time spent in each compartment was recorded for $900 \mathrm{~s}$. Animals showing strong 
unconditioned aversion (less than 33\% of the session time) or preference (more than 67\%) for any compartment were discarded. One compartment was paired with drug and the other with vehicle because in each group, half the animals received the drug or vehicle in the most preferred compartment and the other half in the less preferred. In the second phase (conditioning for $4 \mathrm{~d}$ ), animals received an injection of physiological saline before confinement for $1 \mathrm{~h}$ to the vehicle-paired compartment, and after an interval of $4 \mathrm{~h}$, received the drugs immediately before confinement for $1 \mathrm{~h}$ in the drug-paired compartment. The central area was never used during conditioning and was blocked by guillotine doors. During the third phase or postconditioning (Post-C), on day 8 the guillotine doors were removed, and the time spent in each compartment by untreated mice was recorded during $900 \mathrm{~s}$ of observation. The difference in seconds between the time spent in the drug-paired compartment in the Post $-\mathrm{C}$ test and that spent in the Pre-C one is a measure of the degree of conditioning induced by the drug. If positive, then the drug induced a preference for the drug-paired compartment, whereas the opposite indicates the induction of an aversion.

Experiment 1: Effect of morphine dose on the magnitude of $C P P$. In this experiment 70 mice were assigned to 7 groups, 6 to receive one of 6 doses of morphine used for conditioning $(2,3,5$, $10,20,40 \mathrm{mg} / \mathrm{kg}$, i.p.), and another group was conditioned with saline.

Experiment 2: Maintenance of CPP using two different schedules of extinction. This experiment was started with 20 mice that were assigned to 2 groups, each conditioned with $40 \mathrm{mg} / \mathrm{kg}$ morphine. This dose was selected because the acquisition of a stable and robust CPP is required in most animals. Following the conditioning, and after the postconditioning test on day 8 (Post $\mathrm{C} 1$ ), 3 animals were discarded due to weak CPP expression demonstrated by a low difference between the time spent in the drug-paired compartment in the post-C test and that spent in pre-C $(<60 \mathrm{~s})$. The aim of this experiment was to study the persistence of the CPP with two different schedules of extinction, so we decided that the initial CPP must be readily apparent. The remaining mice were given two different schedules of extinction: one group $(n=8)$ underwent a daily extinction session consisting of the placement of animals in the apparatus (without guillotine doors separating the compartments) for $60 \mathrm{~min}$ (group EXT60), while the other group $(n=9)$ performed the same extinction session but for only $15 \mathrm{~min}$ (group EXT15). In both extinction sessions, the time spent by the animals in each compartment during the first $15 \mathrm{~min}$ was registered (Post-C2). This was repeated until the time spent in drug-paired compartment for each group of animals was similar to those of the Pre-C session.

Experiment 3: Reinstatement of CPP using different primes of morphine. Experiment $3 \mathrm{~A}$ was started with 84 mice conditioned with $40 \mathrm{mg} / \mathrm{kg}$ morphine. After the post-C test on day 8 (Post $\mathrm{C} 1$ ), seven animals were removed from the experiment because of weak CPP expression $(<60 \mathrm{~s})$. The remaining mice were assigned to 7 groups, 6 to receive one of the 6 doses of morphine used for the reinstatement test $(2,3,5,10,20,40 \mathrm{mg} / \mathrm{kg}$, i.p.), and another group was tested for reinstatement with saline. The 7 groups underwent a 15 min extinction schedule: a daily extinction session consisting of placing the animals in the apparatus (without guillotine doors separating the compartments) for 15 min until the time spent in drug-paired compartment for each group was similar to those of Pre-C session. Afterward, on the following day, the effect of the priming doses of morphine on the reinstatement of place preference was evaluated. The tests of reinstatement were the same as those for Post- $\mathrm{Cl}$ except that animals were tested $30 \mathrm{~min}$ after the respective drug injection dose or saline. All priming injections were given in the animalarium, a noncontingent place to previous conditioning injections. 
Experiment 3B served as a replication of part of Experiment $3 \mathrm{~A}$ and was designed to assess whether the extinction observed when the time spent in the drug-paired compartment was similar to that of Pre-C session was stable. This experiment started with 12 mice conditioned with $40 \mathrm{mg} / \mathrm{kg}$ morphine. After the post-conditioning test on day 8 (Post $\mathrm{C} 1$ ), two animals were removed from the experiment due to weak CPP expression $(<60 \mathrm{~s})$. The remaining mice underwent the $15 \mathrm{~min}$ extinction schedule until it was verified for 3 consecutive days that the time spent in drug-paired compartment was similar to that of Pre-C session. On the following day, the effect of a priming dose of $10 \mathrm{mg} / \mathrm{kg}$ of morphine on the reinstatement of place preference was evaluated, following the same protocol used in Experiment 3A.

Experiment $3 \mathrm{C}$ served as a control for Experiment 3A. The aim of this experiment was to demonstrate the lack of effects of a priming dose of morphine on non-conditioned animals. In this experiment we observed the effect of the noncontingent injection of morphine $(10 \mathrm{mg} / \mathrm{kg})$ in animals conditioned with a non-effective dose of morphine $(2 \mathrm{mg} / \mathrm{kg})$. After the post-conditioning test on day 8 (Post $\mathrm{C} 1$ ), 12 mice underwent the 15 min extinction schedule. It was verified that the time spent in drug-paired compartment was similar to that of Pre-C session on 2 consecutive days. On the following day, the effect of a priming dose of $10 \mathrm{mg} / \mathrm{kg}$ of morphine was evaluated, following the same protocol used in Experiment $3 \mathrm{~A}$.

\section{Statistical analysis}

To evaluate the acquisition of CPP, the time spent in the drug-paired compartment during the pre-and post-C phases was analyzed using a two mixed ANOVA with a between variable 'Treatment' (treatment groups) and a within variable 'Days' with 2 levels (pre- and post-C). For post-hoc comparisons, Newman-Keuls and simple effects tests were used. During extinction and reinstatement tests, differences in the time spent in the drug-paired compartment between Pre-C and each extinction session or rein-statement test were analyzed with a Student's $t$ test.

\section{RESULTS}

\section{Experiment 1: Effect of dose of morphine on magnitude of CPP}

The administration of morphine induces CPP (Fig. 1). ANOVA revealed that the variable Days $[F(1,58)=57.312 ; p<0.0001]$ and the Interaction Treatment $\mathrm{X}$ Days $[F(6,58)=2.989 ; p<0.01]$ were significant. Variable Treatment was non significant $[F(6,58)=1,228 ; p<0.305]$. Post-hoc comparisons of the Interaction indicated that the effect of Treatment was significant only on day $2(p<0.01)$ and the effect of Days was significant in groups receiving $5,10,20$ and $40 \mathrm{mg} / \mathrm{kg}$ of morphine $\left(p_{s}<\right.$ 0.001 ), with a significant increase in the time spent in the drug-paired compartment in Post-C in comparison with Pre-C.

\section{Experiment 2: Maintenance of CPP using two different schedules of extinction}

The administration of morphine induced CPP in both groups (see Fig. 2). ANOVA revealed that the variable Days $[F(1,15)=128.765 ; p<0.0001]$ was significant. The variable Treatment $[F(1,15)=$ $0.099 ; p<0.7577]$ and the interaction Treatment $\mathrm{X}$ Days $[F(1,15)=0.187 ; p<0.6712]$ were not significant. Post-hoc comparisons indicated that the effect of Days was significant in both groups $\left(p_{s}<\right.$ 0.001 ) because of a significant increase in the time spent in the drug-paired compartment in Post- $\mathrm{C}$ in comparison with Pre-C.

Morphine-induced CPP lasted up to approximately 1 week. For group EXT60, statistical 
analysis showed a significant difference between Pre-C and post-conditioning tests of the extinction phase Post-C2, Post-C3, Post-C4 ( $\left.p_{s}<0.01\right)$, PostC5, Post-C6 $\left(p_{s}<0.02\right)$ and Post-C7 $(\mathrm{p}<0.03)$. For group EXT15, statistical analysis showed a significant difference between Pre-C and Post-C2 $6\left(p_{s}<0.01\right)$, Post-C7 $-8\left(p_{s}<0.02\right)$ and PostC9 $(\mathrm{p}<0.05)$. Morphine-induced CPP disappeared following several extinction sessions. No significant difference was observed in the time spent in the drug-paired compartment between Pre-C and PostC8 in group EXT60 $(p<0.87)$ and between Pre-C and Post-C10 in group EXT15 ( $p<0.66)$, following 7 and 9 extinction sessions, respectively.

\section{Experiment 3: Reinstatement of CPP using different primes of morphine}

In Experiment $3 \mathrm{~A}$, morphine administration induced CPP in all groups of animals (see Fig. 3a).

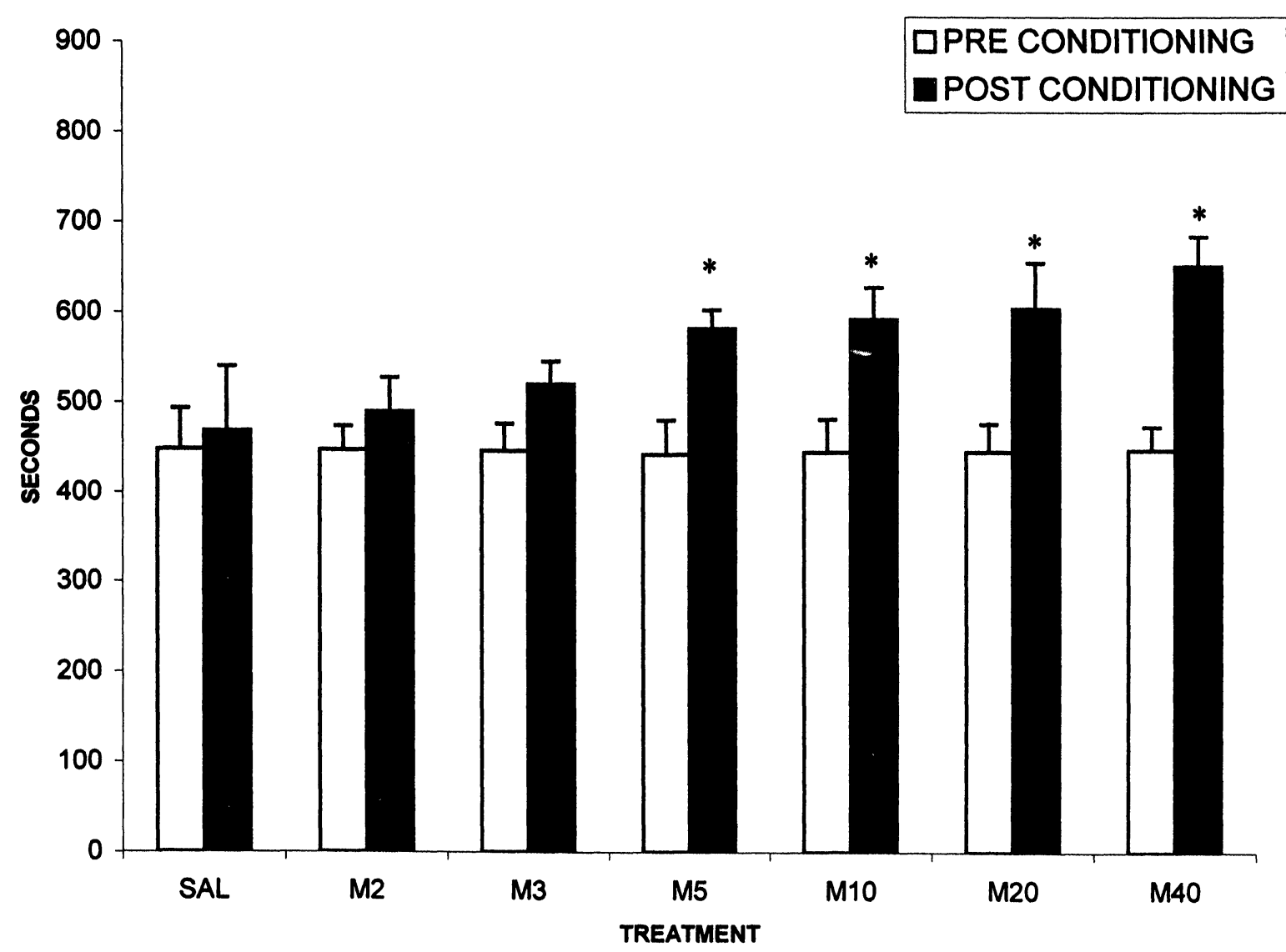

Fig. 1: Effects of different doses of morphine on the acquisition of a CPP. Bars represent the mean $( \pm S E M)$ time spent in the drug-paired compartment before conditioning session $(\square)$ and after conditioning session ( $\boldsymbol{\square}$ ). During conditioning, animals were divided into the following treatment groups: SAL, saline; M2, morphine $2 \mathrm{mg} / \mathrm{kg}$; M3, morphine 3 $\mathrm{mg} / \mathrm{kg}$; M5, morphine $5 \mathrm{mg} / \mathrm{kg}$; M10, morphine $10 \mathrm{mg} / \mathrm{kg}$; M20, morphine $20 \mathrm{mg} / \mathrm{kg}$; M40, morphine $40 \mathrm{mg} / \mathrm{kg}$; ${ }^{*} \mathrm{p}<$ 0.01 , significant difference in time spent in pre-conditioning vs. post-conditioning sessions. 
ANOVA revealed that the variable Days $[\mathrm{F}(1,56)$ $=74.024 ; \mathrm{p}<0.0001]$ was significant. As expected, the variable Treatment $[\mathrm{F}(6,56)=$ $0.346 ; p<0.909$ ] and the Interaction Treatment $X$ Days $[F(6,56)=0.320 ; p<0.9237]$ were nonsignificant as all animals received the same treatment. Post-hoc comparisons indicated that the effect of Days was significant in all groups (ps < 0.001 ), with a significant increase in the time spent in the drug-paired compartment in Post-C in comparison with Pre-C.

After daily extinction sessions in all groups the conditioning disappeared as demonstrated by the lack of significant differences between Pre-C and the last extinction session of each group $(p>1)$. A single non-contingent injection of different doses of morphine reinstated the extinguished CPP for the compartment previously paired with the drug. After the administration of $5,10,20$, and $40 \mathrm{mg} / \mathrm{kg}$ of morphine, the animals spent significantly more time in the drug-paired compartment during reinstatement tests in comparison with Pre-C (ps $<0.01)$.

In Experiment 3B (Fig. 3b), morphine administration induced CPP $(\mathrm{p}<0.01)$. When it is extinguished for 3 consecutive days ( $p s<1$ ), the administration of $10 \mathrm{mg} / \mathrm{kg}$ of morphine in the reinstatement test was effective in the expression of CPP $(p<0.0001)$.

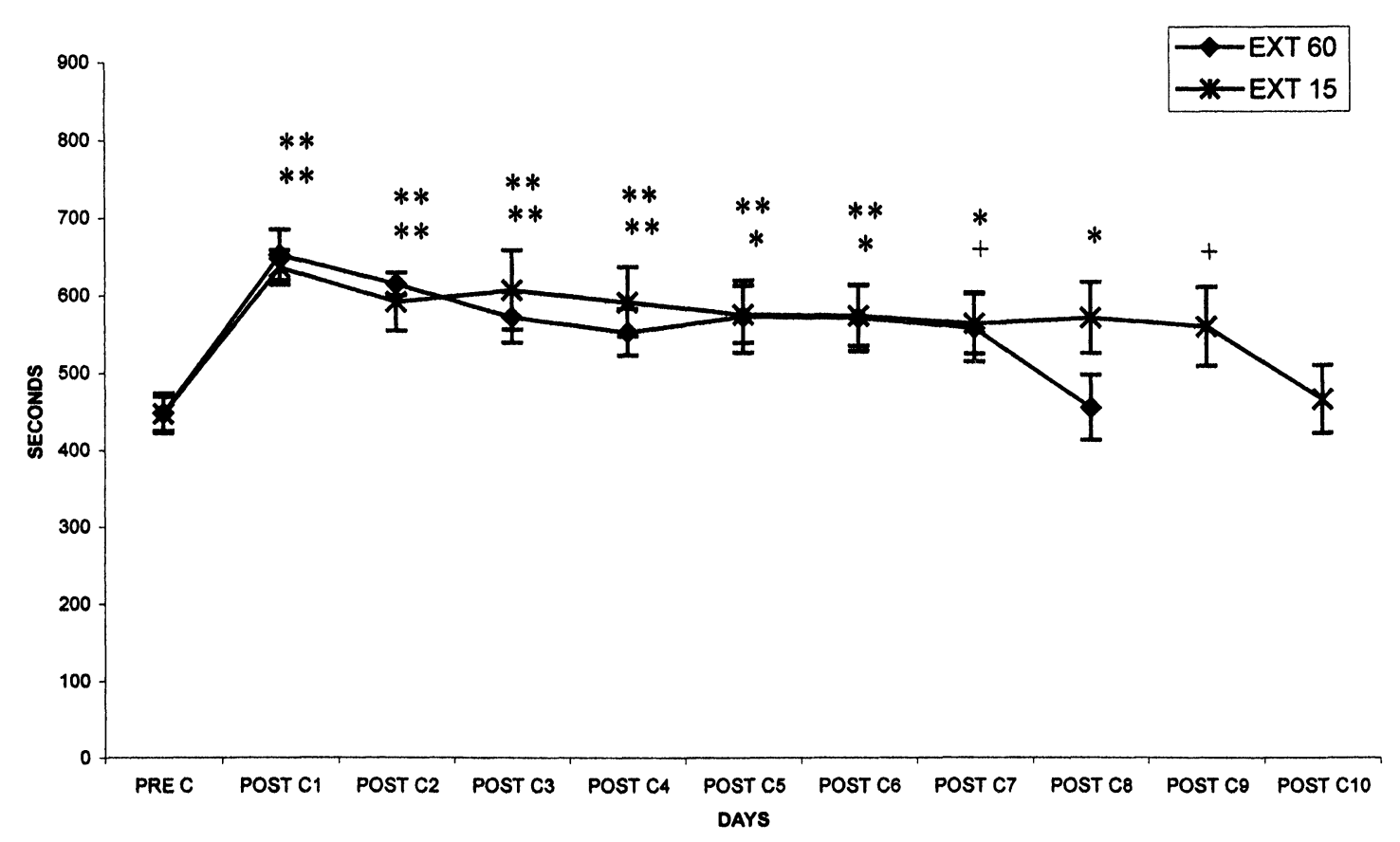

Fig. 2: Maintenance of a morphine-induced CPP. Mean $( \pm \mathrm{SEM})$ time spent in the drug-paired compartment before conditioning sessions (Pre $\mathrm{C}$ ), after conditioning (Post $\mathrm{C} 1$ ) and through daily extinction sessions (POST C2$\mathrm{C} 10)$. Two different schedules of extinction were used: animals placed in the apparatus for 60 min (EXT 60) or for $15 \min (\operatorname{EXT} 15) .{ }^{* *} \mathrm{p}<0.01, * \mathrm{p}<0.02,+\mathrm{p}<0.05$, significant difference in the time spent in preconditioning vs. post-conditioning or extinction sessions. 
In Experiment 3C (Fig. 3c), morphine (2 $\mathrm{mg} / \mathrm{kg}$ ) administration had no effect on CPP, with no significant difference between Pre-C and Post$\mathrm{C}(\mathrm{p}<1)$. When the lack of effect was observed for 3 consecutive days ( $p s<1$ ), the administration of $10 \mathrm{mg} / \mathrm{kg}$ of morphine had no effect $(\mathrm{p}<1)$.

\section{DISCUSSION}

In the present work, we have demonstrated that an extinguished morphine-induced conditioned place preference (CPP) can be reinstated by the non-contingent administration of different priming

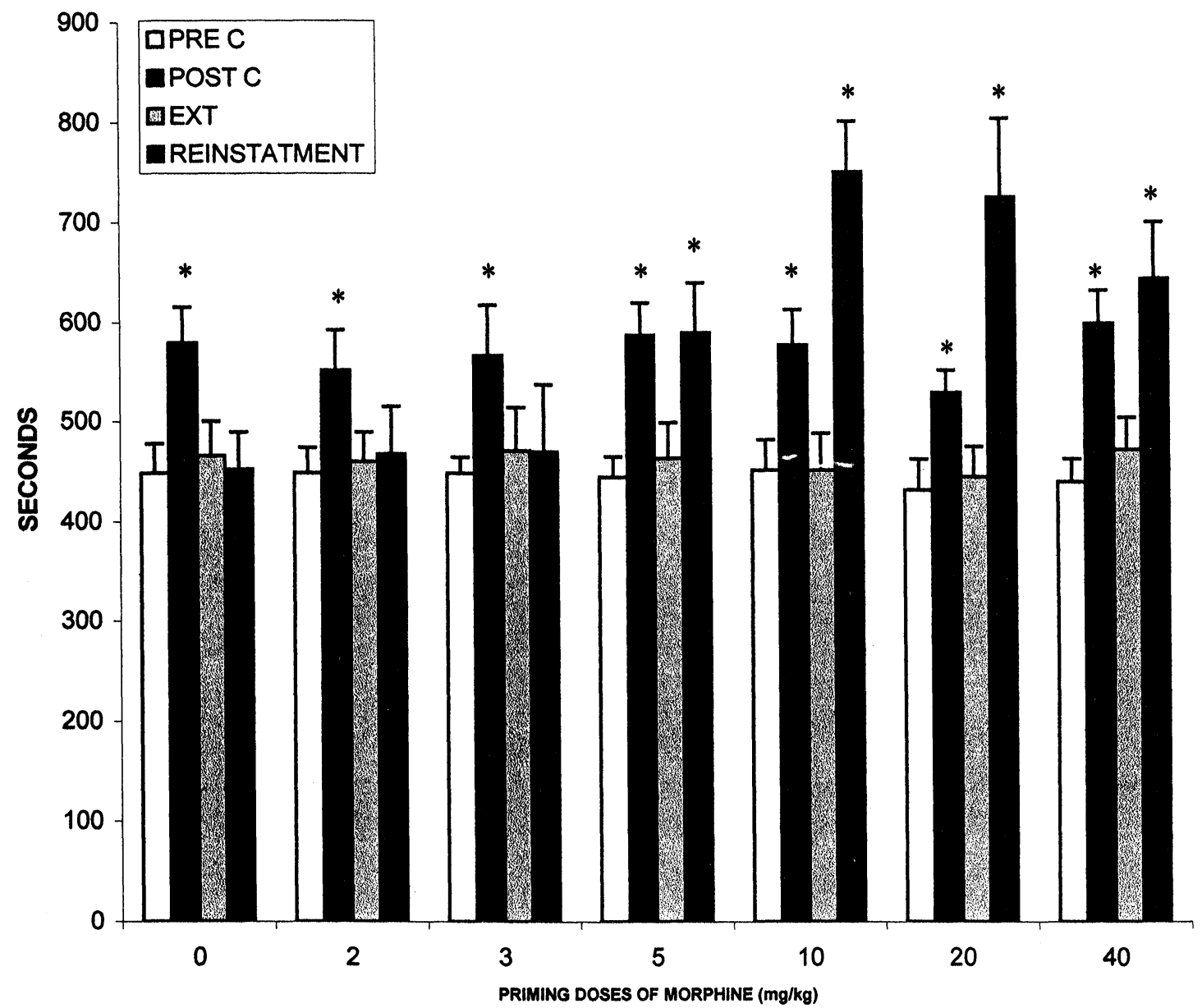

Fig 3: (A) Reinstatement of a previously extinguished morphineinduced CPP by priming doses of morphine. Bars = mean ( \pm SEM) time spent in the drug-paired compartment before conditioning sessions ( $\square$ ), after conditioning sessions ( $\boldsymbol{\square}$ ), in last extinction session (clear gray), and in reinstatement test (dark gray). Animals were conditioned with $40 \mathrm{mg} / \mathrm{kg}$ of morphine and after extinction were tested $30 \mathrm{~min}$ after the following doses of morphine $(0,2,3,5,10,20,40 \mathrm{mg} / \mathrm{kg}) .{ }^{*} \mathrm{p}<0.01$, significant difference in time spent in preconditioning vs. post-conditioning sessions or reinstatement tests. 
doses of morphine in mice. The results suggest that the place-preference paradigm can be useful as a model for studying the mechanisms of druginduced relapse to drug addiction in mice.

The paradigm of place-preference conditioning, based upon the idea that contextual stimuli can acquire conditioned rewarding properties when paired with a primary reinforcer, has been widely used to study the rewarding effects of addictive drugs. Consistently we have observed that the administration of different doses of morphine induces CPP in mice. This result has been repeatedly observed in our and other laboratories (Tzschentke, 1998; Manzanedo et al., 2001b; Manzanedo et al., 2001c; Manzanedo et al., in press). Morphine-induced CPP lasts up to approximately $1 \mathrm{wk}$, when the animals undergo an extinction procedure consisting of their daily exposition to the apparatus for 15 or $60 \mathrm{~min}$. When the period of exposure is for $60 \mathrm{~min}$, the CPP is extinguished 2 days earlier than when the exposure is for $15 \mathrm{~min}$, suggesting that a prolonged exposure to the compartment previously associated with the drug, without experimenting its rewarding effects, slightly facilitates the extinction of CPP. Other studies using this spontaneous extinction of morphine-induced CPP in rats reported similar results, with a lack of conditioning after a 7-d extinguishing period (Wang et al., 2000; 2002). In the present study, the expression of morphineinduced CPP was abolished following repeated exposure of the animals to the apparatus without

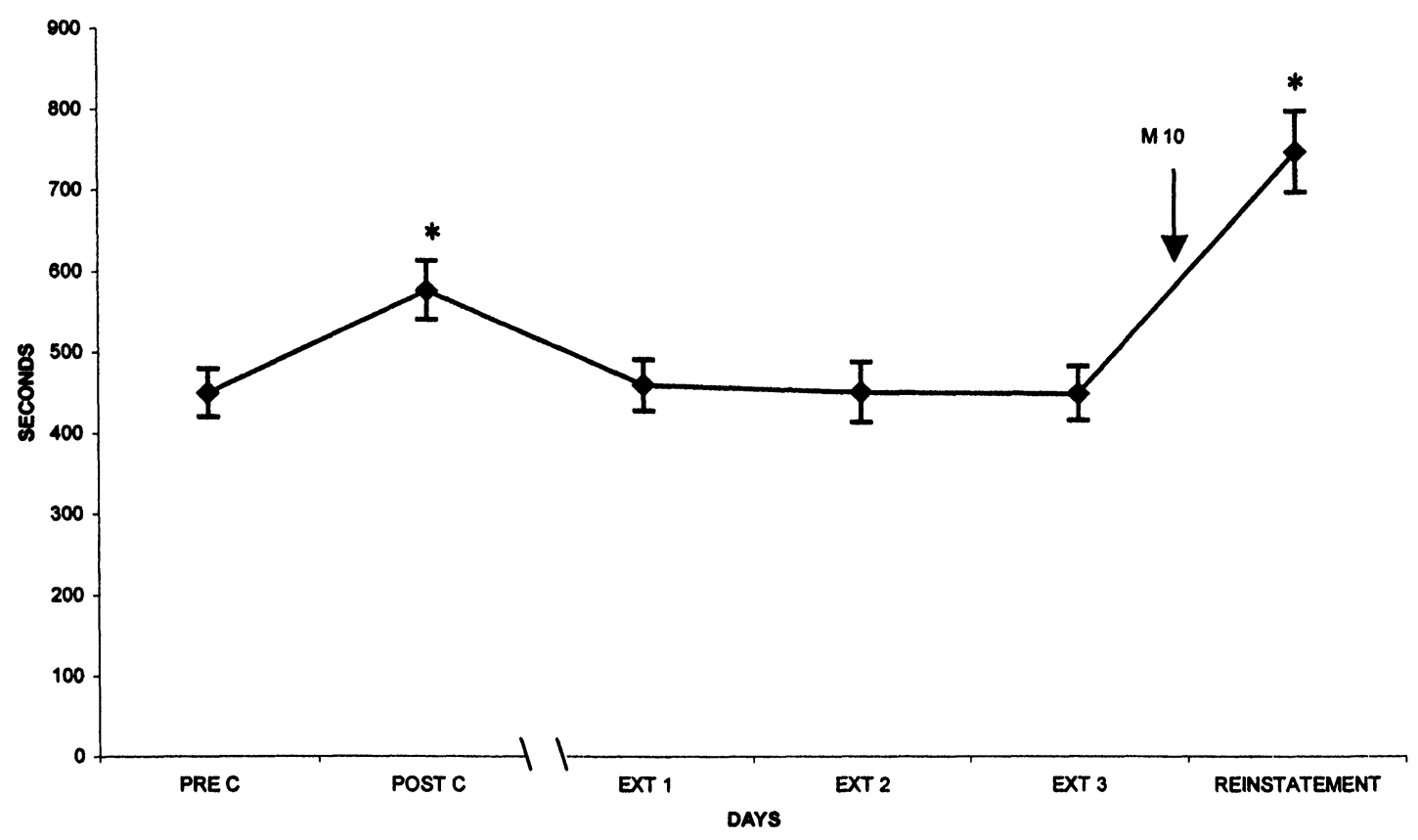

Fig. 3: (B) Effect of a priming dose of $10 \mathrm{mg} / \mathrm{kg}$ of morphine on reinstatement of a repeatedly extinguished morphineinduced CPP. Animals were conditioned with $40 \mathrm{mg} / \mathrm{kg}$ of morphine and acquire a clear CPP, reflected by the significant difference in the time spent in drug-paired compartment between pre-conditioning (PRE C) and postconditioning (POST C). Mice then underwent several extinction sessions until the time spent in the drug-paired compartment was non significantly different to that spent in this compartment during PRE C (EXT 1). After two more consecutive extinction sessions (EXT 2 and EXT 3), animals received a priming dose of $10 \mathrm{mg} / \mathrm{kg}$ of morphine (M10) and $30 \mathrm{~min}$ later were tested for their preference (REINSTATEMENT). ${ }^{*} p<0.01$, significant difference in the time spent in pre-conditioning vs. post-conditioning sessions or reinstatement tests. 
any injection. Compared with other extinction procedures, such as exposure to the environment previously associated with the drug after the administration of saline, the procedure used here is more natural and can more closely model real situations, in which addicted individuals voluntarily stop taking the drug but continue to be exposed to the same stimuli they have associated with drug consumption.

In drug-free human addicts, re-exposure to the self-administered drug induces drug-seeking and precipitates relapse even after long-term periods of abstinence (de Wit, 1996; el-Guebaly, 1998). Reinstatement of responding induced by a priming injection of drugs is widely accepted as a relevant model to study the mechanisms involved in drugcraving and relapse (De Vries, 1998; Shalev et al., 2002) because many studies have reported reliable drug-induced reinstatement of self-administration of heroin, cocaine, alcohol or nicotine (Shaham et al., 1997; Lê et al., 1998; Self \& Nestler, 1998; Stewart, 2000). More recently, drug-induced reinstatement of behavior has been observed using the placeconditioning paradigm (Mueller \& Stewart, 2000; Parker \& McDonald, 2000; Wang et al., 2000; Manzanedo et al., 2001a; Itzhak \& Martin, 2002; $\mathrm{Li}$ et al., 2002; Lu et al., 2002). In accord with these results, we have observed that, after extinction, a single non-contingent injection of different doses of morphine reinstated morphine-

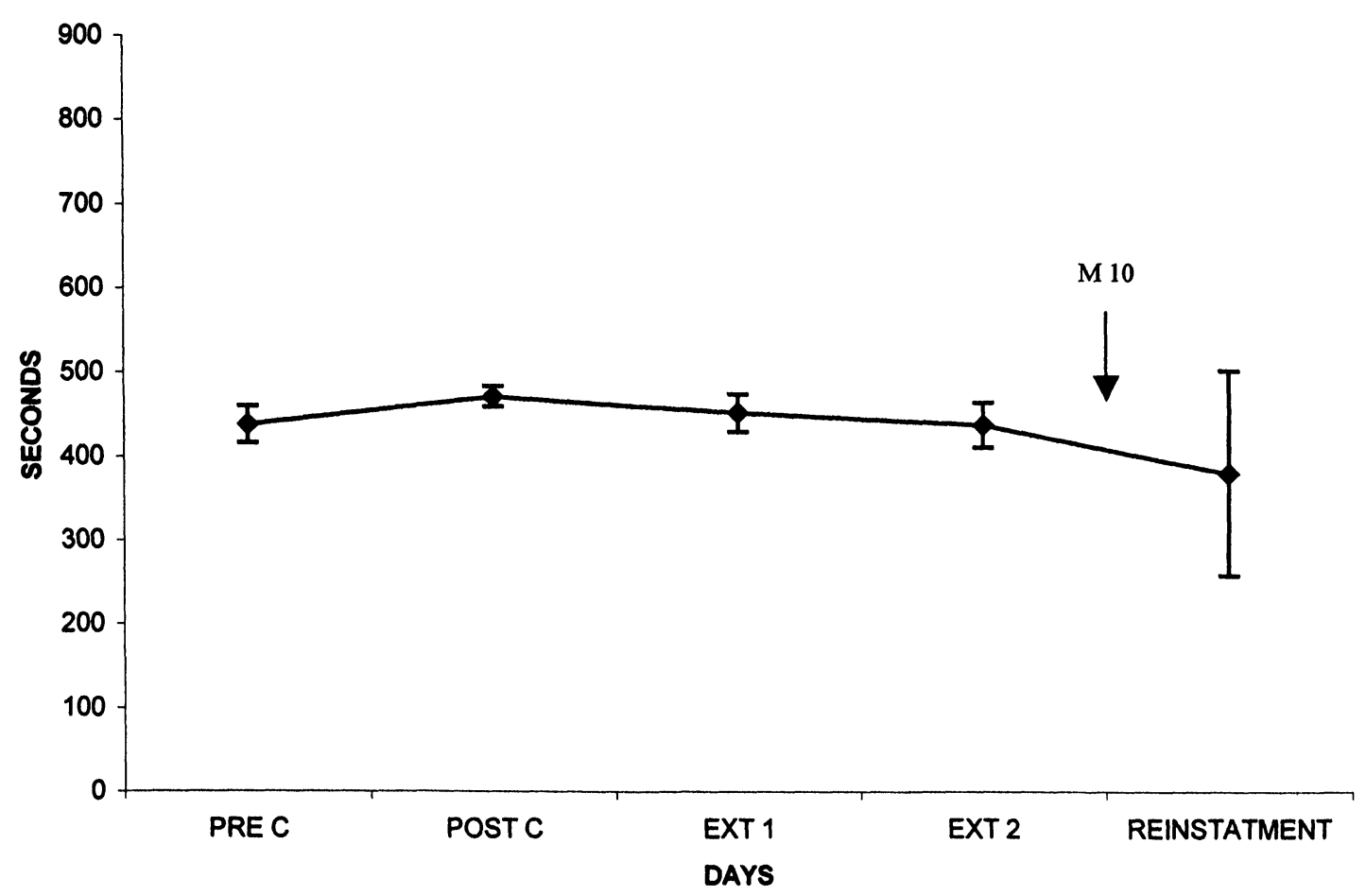

Fig. 3: (C) Lack of effect of a priming dose of $10 \mathrm{mg} / \mathrm{kg}$ of morphine in animals without CPP. Animals were conditioned with $2 \mathrm{mg} / \mathrm{kg}$ of morphine and do not acquire CPP, as is reflected by the lack of significant difference in the time spent in drug paired compartment between pre-conditioning (PRE C) and postconditioning (POST C). Afterwards, mice underwent three consecutive extinction sessions (EXT 1, EXT 2 and EXT 3) and received a priming dose of $10 \mathrm{mg} / \mathrm{kg}$ of morphine (M10) and $30 \mathrm{~min}$ after were tested for their preference (REINSTATEMENT). No significant differences in the time spent in drug-paired compartment in pre-conditioning vs. post-conditioning sessions or reinstatement test were observed. 
induced CPP for the compartment previously paired with the drug. The same result has been previously reported in an initial study carried out by our laboratory in which it was observed that a single injection of $40 \mathrm{mg} / \mathrm{kg}$ of morphine produces the reinstatement of a CPP induced by the same dose of morphine (Manzanedo et al., 2001a). Similarly, other studies using rats as experimental animals demonstrated the reinstating effects of morphine injections after the extinction of morphine-induced CPP (Wang et al., 2000; Lu et al., 2002; Mueller et al., 2002; Parker \& McDonald, 2002; Wang et al., 2002).

The results obtained in the self-administration studies suggest that the activation of $\mu$-opioid receptors is critically involved in heroin-induced reinstatement, since priming injections of $\mu$-opioid receptor agonists such as morphine mimic the effect of heroin on reinstatement (Stewart \& Wise, 1992), while naltrexone, a preferentially $\mu$-opioid receptor antagonist, blocks reinstatement induced by heroin (Shaham \& Stewart, 1996). Moreover, DA mechanisms are also involved in this effect because the activation of DA neurons in the ventral tegmental area (VTA) mediates heroininduced reinstatement of self-administration of this drug (Stewart, 1984). Similarly, a recent study demonstrated that the reinstating effect of drug priming on morphine-induced CPP can be abolished by lesions of the VTA and the shell of the nucleus accumbens (Wang et al., 2002). The involvement of DA in drug-induced reinstatement of a previously extinguished morphine-induced CPP, using DA antagonists, is being currently studied in our laboratory.

The reinstating effects of morphine primes can be attributed to the hedonic properties of the drug, which produces an incentive motivational state that reinstates the preference. Moreover, the drug primes could recall the extinguished CPP. In the placeconditioning paradigm, several neutral environmental stimuli (cues) acquire a positive valence or salience through the pairing with the rewarding effects of the drug. After the extinction of CPP, the reinstatement of this behavior following a priming injection of the drug could be explained as a "renovation" or "restoration" of the significance or attractiveness of the drug-paired environmental stimuli, which leads the animal to approach and stay in the presence of those cues. Moreover, the approach behavior could reflect a reinstatement of craving that again leads the animal to look for those environmental stimuli associated with the presence of the drug. According to Mueller and Stewart (2000), the priming injection "reminds" the animal of the significance of those cues previously paired with the drug.

Another explanation for the priming effect of morphine administration can be focused on the discriminative stimuli properties of this drug and on the idea that the reinstatement of CPP can be due to a state-dependent learning phenomenon. The stimulus properties of morphine are present during conditioning but not during extinction tests. If the expression of CPP were state-dependent, then the animals would be expected to show CPP only in the presence of the drug. Following this hypothesis, exposure to morphine during the tests of reinstatement would elicit a selective increase in the response previously associated with the drug. From our point of view, it appears unlikely that the discriminative stimulus properties of the priming morphine injections could account for their effect on reinstatement of morphine-induced CPP for two reasons. First, because in the placeconditioning paradigm the drug is not associated with a specific instrumental response, it is unlikely that drug primes induce the response habitually elicited by the drug's discriminative stimulus properties. Moreover, during the post-conditioning test, on the first day after training, animals showed a clear CPP, although they did not receive any treatment or injection this day. Second, different neuronal substrates seem to mediate the discriminative stimulus effects and drug-induced 
reinstatement (Jaeger \& van der Kooy, 1996).

Our results confirm the idea that the CPP paradigm can be used in mice as a model of relapse to drug-seeking behavior, a core feature of drug addiction. As in the self-administration paradigm, morphine primes following extinction reinstate morphine-induced CPP. In future studies, it would be very interesting to determine the involvement of several neurotransmitter systems, for instance the dopamine and glutamate, in the reinstatement of conditioned reward induced by drug priming.

\section{ACKNOWLEDGMENTS}

This work was supported by grants: Centro Superior de Investigación en Salud Publica (CSISP), Conselleria de Sanitat, Generalitat Valenciana; Instituto de Salud "Carlos III" (FIS), Redes Temáticas de Investigación Cooperativa (G03/005) (Spain); Bruno Ribeiro Do Couto was supported by grant SFRH/BD/4559/ 2001 of the Fundação Para a Ciência e a Tecnologia, Ministério da Ciência e da Tecnologia (Portugal).

\section{REFERENCES}

Carroll ME, Comer SD. 1996. Animal models of relapse. Exp Clin Psychopharmacol 4: 11-18.

Carter BL, Tiffany ST. 1999. Meta-analysis of cuereactivity in addiction research. Addiction 94: 327-340.

De Vries TJ, Schoffelmeer AN, Binnekade R, Mulder AH, Vanderschuren LJ. 1998. Drug-induced reinstatement of heroin- and cocaine-seeking behaviour following long-term extinction is associated with expression of behavioural sensitization. Eur $\mathbf{J}$ Neurosci 10: 3565-3571.

de Wit H. 1996. Priming effects with drugs and other reinforcers. Exp Clin Psychopharmacol 4: 5-10.

el-Guebaly N, Hodgins D. 1998. Substance-related cravings and relapses: clinical implications. Can J Psychiatry 43: 29-36.
Itzhak Y, Martin JL. 2002. Cocaine-induced conditioned place preference in mice: induction, extinction and reinstatement by related psychostimulants. Neuropsychopharmacology 26: 130-134.

Jaeger TV, van der Kooy D. 1996. Separate neural substrates mediate the motivating and discriminative properties of morphine. Behav Neurosci 110: 181-201.

Lê AD, Quan B, Juzystch W, Fletcher PJ, Joharchi N, Shaham Y. 1998. Reinstatement of alcohol-seeking by priming injections of alcohol and exposure to stress in rats. Psychopharmacology 135: 169-174.

Li SM, Ren YH, Zheng JW. 2002. Effect of 7 nitroindazole on drug-priming reinstatement of $D$ methamphetamine-induced conditioned place preference. Eur J Pharmacol 443: 205-206.

Lu L, Xu NJ, Ge X, Yue W, Su WJ, Pei G, et al. 2002. Reactivation of morphine conditioned place preference by drug priming: role of environmental cues and sensitization. Psychopharmacology 159: 125-132.

Manzanedo C, Aguilar MA, Rodríguez-Arias M, Miñarro J. 2001a. Conditioned place preference can be a mouse model of relapse to opiates. Neurosci Res Com 28: 23-29.

Manzanedo C, Aguilar MA, Rodríguez-Arias M, Miñarro J. 2001b. Effects of dopamine antagonists with different receptor blockade profiles on morphine-induced place preference in male mice. Behav Brain Res 121: 189-197.

Manzanedo C, Serrano A, Aguilar MA, RodríguezArias M, Miñarro J. 2001c. Effects of CGS 10746B on morphine-induced hyperactivity and place preference. Behav Brain Res 126: 23-32.

Manzanedo C, Aguilar MA, Rodríguez-Arias M, Navarro M, Miñarro, J. (in press). 7-Nitroindazole blocks conditioned place preference but not hyper- activity induced by morphine. Behav Brain Res.

Mendelson JH, Mello NK. 1996. Management of cocaine abuse and dependence. $\mathrm{N}$ Engl $\mathrm{J}$ Med 334: 965-972.

Mueller D, Stewart J. 2000. Cocaine-induced conditioned place preference: reinstatement by priming injections of cocaine after extinction. Behav Brain Res 115: 39-47.

Mueller D, Perdolaros D, Stewart J. 2002. Persistence and drug-induced reinstatement of a morphineinduced conditioned place preference. Behav Brain Res 136: 389-397. 
O'Brien CP. 1997. A range of research-based pharmacotherapies for addiction. Science, 1997; 278: $66-70$.

Parker LA, McDonald RV. 2000. Reinstatement of both a conditioned place preference and a conditioned place aversion with drug primes. Pharmacol Biochem Behav 66: 559-561.

Sanchez CJ, Sorg BA. 2001. Conditioned fear stimuli reinstate cocaine-induced conditioned place preference. Brain Res 908: 86-92.

Self DW, Nestler EJ. 1998. Relapse to drug-seeking: neural and molecular mechanisms. Drug Alcohol Depend 51: 49-69.

Shaham Y, Stewart J. 1996. Effects of opioid and dopamine receptor antagonists on relapse induced by stress and reexposure to heroin in rats. Psychopharmacology 125: 385-391.

Shaham Y, Adamson LK, Grocki S, Corrigall WA. 1997. Reinstatement and spontaneous recovery of nicotine-seeking in rats. Psychopharmacology 130: 396-403.

Shalev U, Grimm JW, Shaham Y. 2002. Neurobiology of relapse to heroin and cocaine seeking: a review. Pharmacol Reviews 54: 1-42.

Sinha R, Catapano D, O'Mally S. 1999. Stress-induced craving and stress responses in cocaine dependent individuals. Psychopharmacology 142: 343-351.

Stewart J. 1984. Reinstatement of heroin and cocaine self-administration behavior in the rat by intracerebral application of morphine in the ventral tegmental area. Pharmacol Biochem
Behav 20: 917-923.

Stewart J. 2000. Pathways to relapse: the neurobiology of drug- and stress-induced relapse to drug-taking. J Psychiatry Neurosci 25: 125-136.

Stewart J, Wise RA. 1992. Reinstatement of heroin self-administration habits: morphine prompts and naltrexone discourages renewed responding after extinction. Psychopharmacology 108: 79-84.

Szumlinski KK, Price KL, Frys KA, Middaugh LD. 2002. Unconditioned and conditioned factors contribute to the "reinstatement" of cocaine place conditioning following extinction in C57BL/6 mice. Behav Brain Res 136: 151-160.

Tzschentke TM. 1998. Measuring reward with the conditioned place preference paradigm: a comprehensive review of drug effects, recent progress and new issues. Progress Neurobiol 56: 613-672.

Wang B, Luo F, Zhang WT, Han JS. 2000. Stress or drug priming induces reinstatement of extinguished conditioned place preference. Neuroreport 11: 2781-2784.

Wang B, Cen X, Lu L. 2001. Noradrenaline in the bed nucleus of the stria terminalis is critical for stress-induced reactivation of morphineconditioned place preference in rats. Eur $\mathrm{J}$ Pharmacol 432: 153-161.

Wang B, Luo F, Ge X-C, Fu A-H, Han J-S. 2002. Effects of lesions of various brain areas on drug priming or footshock-induced reactivation of extinguished conditioned place preference. Brain Res 950: 1-9. 

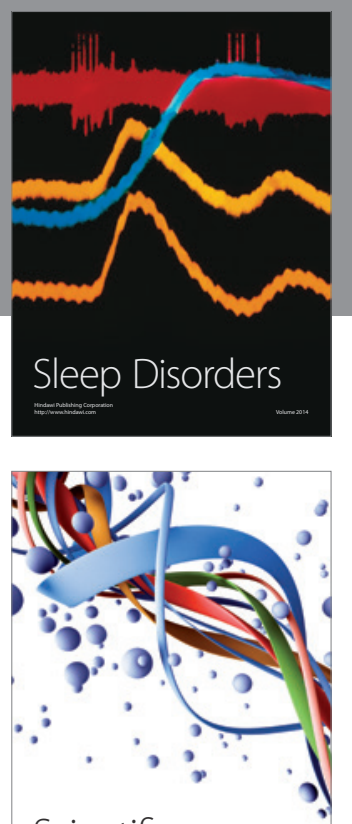

Scientifica
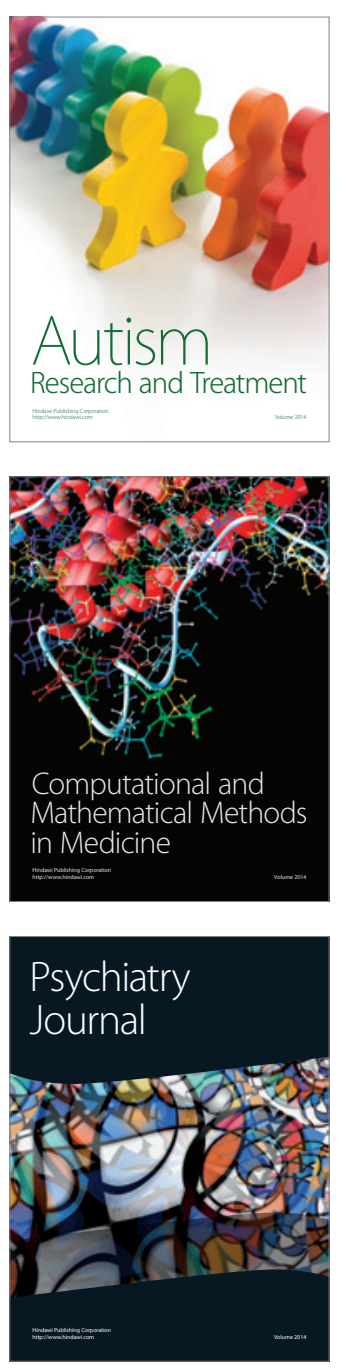
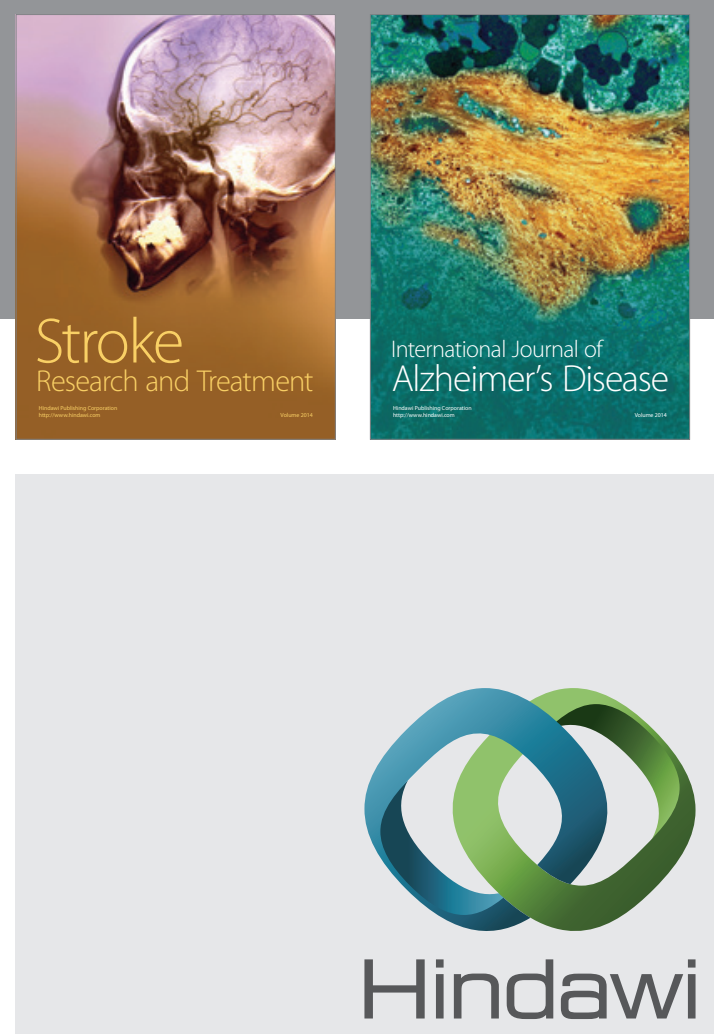

Submit your manuscripts at

http://www.hindawi.com
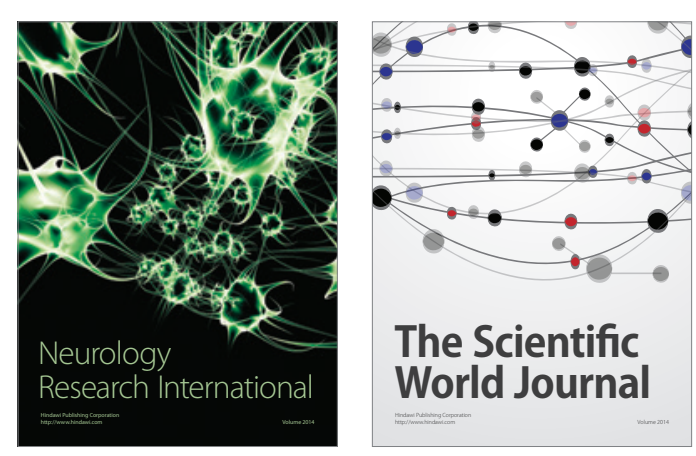

The Scientific World Journal

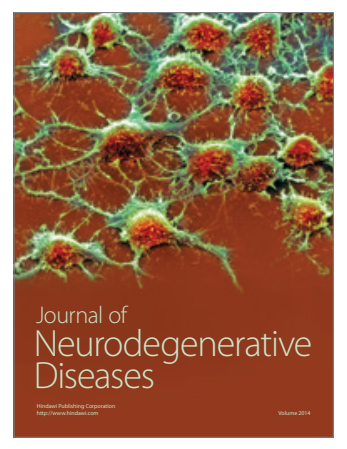

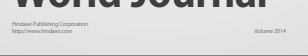

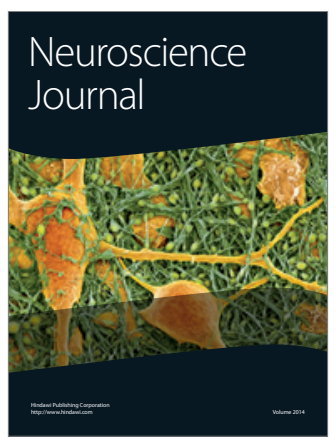

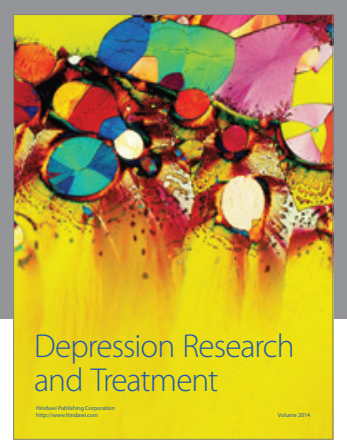
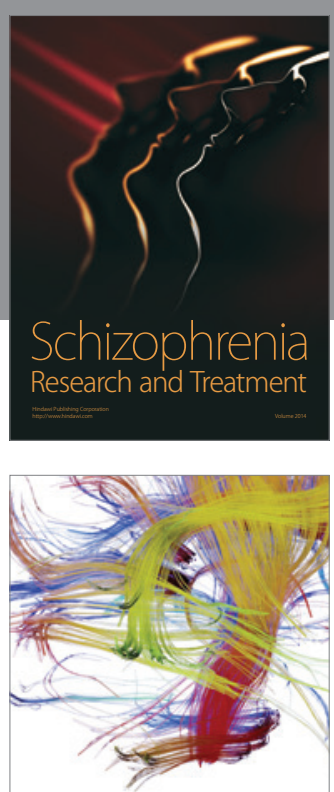

Brain Science

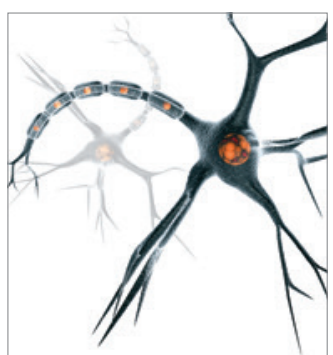

Neural Plasticity
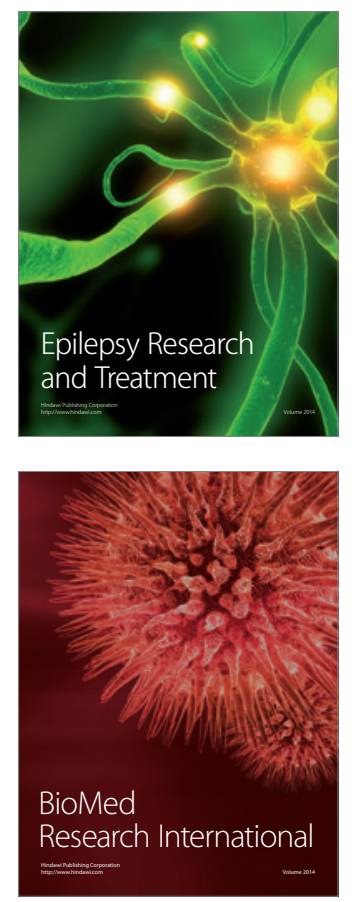

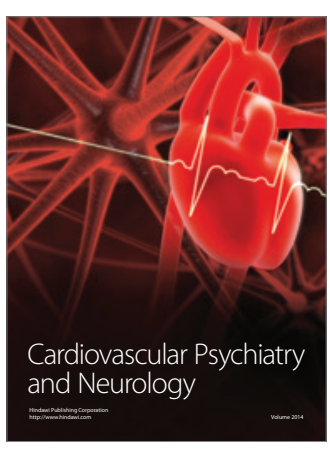

Parkinson's

Disease
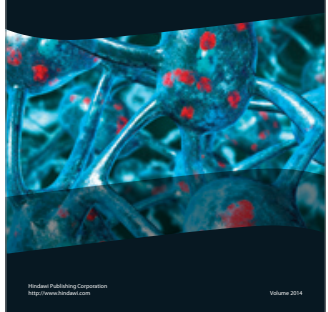